\title{
The Volitional Nature of Nicotine Exposure Alters Anandamide and Oleoylethanolamide Levels in the Ventral Tegmental Area
}

\author{
Matthew W Buczynski', Ilham Y Polis' and Loren H Parsons*,' \\ 'Committee on the Neurobiology of Addictive Disorders, The Scripps Research Institute, La Jolla, CA, USA
}

\begin{abstract}
Cannabinoid-I receptors $\left(C B_{1}\right)$ have an important role in nicotine reward and their function is disrupted by chronic nicotine exposure, suggesting nicotine-induced alterations in endocannabinoid (eCB) signaling. However, the effects of nicotine on brain eCB levels have not been rigorously evaluated. Volitional intake of nicotine produces physiological and behavioral effects distinct from forced drug administration, although the mechanisms underlying these effects are not known. This study compared the effects of volitional nicotine self-administration (SA) and forced nicotine exposure (yoked administration (YA)) on levels of eCBs and related neuroactive lipids in the ventral tegmental area (VTA) and other brain regions. Brain lipid levels were indexed both by in vivo microdialysis in the VTA and lipid extractions from brain tissues. Nicotine SA, but not YA, reduced baseline VTA dialysate oleoylethanolamide (OEA) levels relative to nicotine-naïve controls, and increased anandamide (AEA) release during nicotine intake. In contrast, all nicotine exposure paradigms increased VTA dialysate 2-arachidonoyl glycerol (2-AG) levels. Thus, nicotine differentially modulates brain lipid (2-AG, AEA, and OEA) signaling, and these modulations are influenced by the volitional nature of the drug exposure. Corresponding bulk tissue analysis failed to identify these lipid changes. Nicotine exposure had no effect on fatty acid amide hydrolase activity in the VTA, suggesting that changes in AEA and OEA signaling result from alterations in their nicotine-induced biosynthesis. Both $C_{1}$ (by AEA and 2-AG) and non-CB, (by OEA) targets can alter the excitability and activity of the dopaminergic neurons in the VTA. Collectively, these findings implicate disrupted lipid signaling in the motivational effects of nicotine.
\end{abstract}

Neuropsychopharmacology (2013) 38, 574-584; doi:10.1038/npp.2012.210; published online 21 November 2012

Keywords: nicotine; endocannabinoid; anandamide; 2-arachidonoylglycerol; oleoylethanolamide; ventral tegmental area

\section{INTRODUCTION}

Recent preclinical and clinical studies demonstrate an important involvement of cannabinoid-1 receptor $\left(\mathrm{CB}_{1}\right)$ in the etiology of nicotine addiction. Several studies have demonstrated nicotine-induced alterations in brain $\mathrm{CB}_{1}$ receptor expression and function (Gerard et al, 2010; Marco et al, 2007; Werling et al, 2009). Screening of two independent clinical populations revealed that $\mathrm{CB}_{1}$ gene variants are associated with nicotine dependence (Chen et al, 2008) and the $\mathrm{CB}_{1}$ receptor antagonist Rimonabant (SR141716A) prolonged abstinence rates in smokers expressing motivation to quit (Le Foll et al, 2008). SR141716A and the related $\mathrm{CB}_{1}$ antagonist AM251 reduce nicotine selfadministration (SA) by rats (Cohen et al, 2002, 2005; Forget et al, 2009; Shoaib, 2008), attenuate nicotine-induced increases in nucleus accumbens (NAc) dopamine (DA)

*Correspondence: Dr LH Parsons, Committee on the Neurobiology of Addictive Disorders, The Scripps Research Institute, 10550 North Torrey Pines Road, La Jolla, CA 92037, USA, Tel: + I 858784 7413, Fax: + I 858784 7405, E-mail: Iparsons@scripps.edu.

Received 26 June 2012; revised 8 September 2012; accepted 25 September 2012
(Cheer et al, 2007; Cohen et al, 2002; Grieder et al, 2012), and reduce reinstatement of nicotine-seeking behavior in animal models of relapse (Forget et al, 2009). Collectively, these findings provide strong evidence for a $\mathrm{CB}_{1}$ receptor involvement in the motivational effects produced by nicotine, and imply a role for endocannabinoid (eCB) signaling in this process.

To date, only one study has directly evaluated brain eCB content following nicotine exposure. Gonzalez and coworkers (2002) reported that repeated daily subcutaneous nicotine injections produce regionally selective alterations in rat brain bulk tissue levels of the eCBs, anandamide (AEA), and 2-arachidonoyl glycerol (2-AG), measured $2 \mathrm{~h}$ postinjection using mass spectrometry analysis. This technique has been the predominant method for measuring eCB changes, and it allows for rapid evaluation of regionspecific effects; however, limitations of this approach (necessary euthanasia, indistinguishable extracellular/intracellular pools) may prevent it from accurately representing synaptically relevant changes (Buczynski and Parsons, 2010). By contrast, in vivo microdialysis avoids the requirement for euthanasia before sample collection and better differentiates between extracellular $v s$ intracellular lipid pools. Moreover, microdialysis indexes neuronally 
derived $\mathrm{eCB}$ release as demonstrated by tetrodotoxinsensitive depolarization-induced increases in dialysate AEA and 2-AG levels (Buczynski et al, 2010; Giuffrida et al, 1999). For these reasons, in vivo microdialysis likely provides a more accurate index of drug-induced changes in synaptically relevant eCB levels than do bulk tissue measures.

The volitional nature of nicotine exposure may exert an important influence on nicotine-induced alterations in brain eCB signaling. Substantial evidence demonstrates that volitional (actively intended) drug intake produces distinct physiological, biochemical, and behavioral effects when compared with forced drug administration. For example, the response contingency of drug exposure robustly influences gene expression (Jacobs et al, 2002, 2003, 2005), neural activation (Chang et al, 1994; Peoples and West, 1996; Stuber et al, 2005), and resultant extracellular neurochemistry (Di Ciano et al, 1996; Hemby et al, 1997; Jacobs et al, 2003; Lecca et al, 2007; Orejarena et al, 2009; You et al, 2007). With specific regard to nicotine, differential effects of volitional SA $v s$ forced drug administration have been observed on $\alpha_{4} \beta_{2}$ nAChR expression (Metaxas et al, 2010), cortical glutamatergic projection activity and plasticity mechanisms in the ventral tegmental area (VTA) (McFarland et al, 2003; You et al, 2007), and plasma corticosterone levels (Donny et al, 2000). Because nAChR, glutamate (GLU), and glucocorticoid signaling robustly influence eCB production (Di et al, 2003, 2005; Hill et al, 2010a, c), self-administered nicotine may produce distinct effects from forced nicotine exposure on brain eCB signaling.

This study explores the differential effects of volitional nicotine SA and non-volitional forced nicotine administration on brain eCB levels. Rats given access to nicotine SA were compared with rats that received the same history of nicotine infusion patterns using a response-independent yoked administration (YA) design (Hemby et al, 1997; Smith et al, 1982, 2003). To provide a temporal correlation between drug exposure and changes in brain eCB levels, we employed in vivo microdialysis to sample interstitial lipids in the VTA, a region critically involved in the mediation of nicotine reward and addiction (Markou, 2008). For comparative purposes and initial evaluation of regional differences in nicotine-induced changes, an additional study compared the effects of nicotine SA vs YA on brain tissue levels of eCBs and $n$-arachidonoyl conjugates of neurotransmitters (NA-NTs) in the VTA and six additional regions of interest. Overall, the results show that brain eCBs and related lipids are differentially affected by volitional $v s$ forced nicotine administration. Moreover, these findings demonstrate the independent regulation of $A E A, 2-A G$, palmitoylethanolamide (PEA), OEA, and various NA-NTs, and underscore the differences between in vivo microdialysis and post-mortem tissue extractions for indexing levels of neuroactive lipids in the brain.

\section{MATERIALS AND METHODS}

\section{Animals}

Male Wistar rats (350-450 g; Charles River Laboratories, Wilmington, MA) were housed in a temperature-controlled vivarium $\left(22^{\circ} \mathrm{C}\right)$ with a $12 \mathrm{~h}$ light/dark cycle and given ad libitum access to water and controlled access to food (described below). Tests were performed at the beginning of the dark cycle. The studies were conducted in accordance with the NIH Guide for Care and Use of Laboratory Animals.

\section{Surgery}

All rats had an intravenous catheter surgically implanted into the jugular vein and were allowed 1 week to recover before experimentation (Caille et al, 2007). For microdialysis studies, rats were implanted with a microdialysis guide cannula (SciPro, Sanborn, NY) aimed at the VTA (AP $=-4.8 \mathrm{~mm}$, bregma; $\mathrm{ML}= \pm 0.8 \mathrm{~mm}$, bregma; $\mathrm{DV}=-7.2 \mathrm{~mm}$, dura) (Paxinos and Watson, 1998) before any drug treatment.

\section{Nicotine Administration Procedures}

For volitional nicotine exposure, (SA) rats were trained to respond operantly for intravenous nicotine $(75 \mu \mathrm{g} / \mathrm{kg}$ per infusion; $0.1 \mathrm{ml}$ per infusion over $4 \mathrm{~s}$ ) under an FR-1 schedule in daily 2 -h sessions using procedures similar to those described previously (Caille et al, 2007). Food access was restricted to $10-15 \mathrm{~g}$ per rat per day until operant behavior was acquired, and maintained at $25 \mathrm{~g}$ per rat per day throughout the remainder of the experiment. Rats receiving non-contingent forced nicotine exposure (YA) were individually paired with animals in the SA group and received an identical pattern of nicotine infusions to their partner rat's SA session from the previous day. Rats receiving acute non-contingent forced nicotine exposure (Acute) were also individually paired with animals in the SA group and received an identical pattern of nicotine infusions only during the final session.

\section{Effect of Nicotine Exposure on Lipid Levels in Regional Brain Bulk Tissue}

Rats were given 17 sessions of nicotine SA $(n=14)$ or YA $(n=12)$. A drug-naïve group $(n=10)$ received 17 daily 2 -h sessions in which operant responses resulted in intravenous saline infusion $(0.1 \mathrm{ml}$ per infusion). At $1 \mathrm{~h}$ into the $18 \mathrm{th}$ nicotine session, animals were killed by $\mathrm{CO}_{2}$ asphyxiation and brains were dissected (Supplementary Methods and Supplementary Figure S1) for the prefrontal cortex (PFC), NAc, dorsal striatum (DS), amygdala (AMGY), hippocampus (HIPP), VTA, and substantia nigra (SNr). Lipid content was determined using LC-MS/MS (Agilent 6410) multiplereaction monitoring in positive ion mode. Briefly, 12 tissue lipid species were measured (Supplementary Table S1): 2AG, AEA, AdEA, NA-DA, OL-DA, NA-5HT, PEA, OEA, NE, NA-GLU, NA-taurine (TAU), and NA- $\gamma$-aminobutyric acid (GABA). Quantitative analysis was performed by the stable isotope dilution quantification method using internal standards: $\mathrm{d}_{5}-2-\mathrm{AG}, \mathrm{d}_{4}-\mathrm{AEA}, \mathrm{d}_{4}-\mathrm{PEA}$, and $\mathrm{d}_{4}-\mathrm{NA}-\mathrm{DA}$.

\section{Effect of Nicotine Exposure on Lipid Levels Measured by In Vivo Microdialysis}

Rats were given 36 sessions of nicotine SA $(n=12)$ or YA $(n=9)$. An additional Acute group $(n=9)$ of drug-naïve rats was also prepared. On the evening before microdialysis collections, microdialysis probes (1-mm active membrane) 
were inserted through the guide cannulae and perfused overnight with artificial cerebral spinal fluid as described previously (Caille et al, 2007). On the subsequent day, dialysate samples were collected at 15-min intervals for $90 \mathrm{~min}$ of baseline, $120 \mathrm{~min}$ of nicotine exposure (SA, YA, or Acute), and an additional $60 \mathrm{~min}$ post-drug. Dialysate eCB levels were analyzed by LC-MS using previously described methods (Caille et al, 2007), that is, by using deuterated internal standards $\left(\mathrm{d}_{4}-\mathrm{AEA}, \mathrm{d}_{4}-\mathrm{PEA}, \mathrm{d}_{4}\right.$-OEA, and $\left.\mathrm{d}_{5}-2-\mathrm{AG}\right)$ and the stable isotope dilution quantification method.

\section{Effect of Nicotine Exposure on FAAH Activity}

Rats from the Acute, YA, and SA groups were killed by $\mathrm{CO}_{2}$ asphyxiation at $2 \mathrm{~h}$ after the final nicotine exposure, and their brains snap-frozen and stored at $-80^{\circ} \mathrm{C}$. Brains were sliced $(50 \mu \mathrm{m})$ at $-10^{\circ} \mathrm{C}$ to confirm probe placement into the VTA, and the alternate side was sliced $(500 \mu \mathrm{m})$ and punched for the VTA (Supplementary Methods). Brain punches were processed and analyzed for fatty acid amide hydrolase (FAAH) activity using previously published methodology (Long et al, 2009). VTA punches were homogenized in icecold PBS, and FAAH activity determined by incubating $100 \mu \mathrm{l}$ of protein homogenate $(0.5 \mathrm{mg} / \mathrm{ml}, \mathrm{PBS})$ with $100 \mu \mathrm{M} \mathrm{d} \mathrm{d}_{8}$-AEA in glass vials $\left(37^{\circ} \mathrm{C}\right.$ for $\left.30 \mathrm{~min}\right)$. The reaction was quenched with stop solution ( $300 \mu \mathrm{l}, 2: 1$ chloroform:methanol, $5 \mathrm{nmol}$ pentadecanoic acid). Samples were vortexed and centrifuged ( 2400 r.p.m., $4{ }^{\circ} \mathrm{C}, 10 \mathrm{~min}$ ), and $30 \mu \mathrm{l}$ of the organic layer was analyzed for $\mathrm{d}_{8}$-AEA hydrolysis via single ion monitoring in negative-ion mode using $\mathrm{d}_{8}$-arachidonic acid $(-311 \mathrm{~m} / z)$ as the reaction product and pentadecanoic acid $(-241 \mathrm{~m} / z)$ as the internal standard. Data were expressed as relative activity to naïve (control) rats.

\section{Statistics}

Statistical analyses were performed using PASW Statistics (Version 18). For tissue lipid data, statistical significance was determined by ANOVA followed by a single false discovery rate analysis ( $v$ s naïve ${ }^{*} p<0.05$, vs $\mathrm{YA}^{*} \mathrm{p}<0.05$; for details see Supplementary Information; Pike, 2011). For microdialysis lipid data, statistical significance was determined by repeated-measures ANOVA $\left({ }^{*} p<0.05, \quad{ }^{* *} p<0.01\right.$, and $\left.{ }_{* * *} p<0.001\right)$ for effects of group, nicotine, and group $x$ nicotine interaction. Here, groups were defined as drug history (Acute $v s$ YA) and contingency (YA $v s$ SA). Effect of nicotine on each individual condition was determined by ANOVA $\left({ }^{*} p<0.05,{ }^{* *} p<0.01\right.$, and $\left.{ }^{* * *} p<0.001\right)$. Statistical significance for microdialysis baseline levels and AUC values was determined by ANOVA followed by Fisher's PLSD $\left({ }^{\star} p<0.05,{ }^{* *} p<0.01\right.$, and $\left.{ }^{* * *} p<0.001\right)$.

\section{RESULTS}

\section{Effect of Volitional (SA) vs Forced (YA) Nicotine Exposure on VTA eCB and Ethanolamide Levels Measured by In Vivo Microdialysis}

The SA group $(n=12)$ received a total of $48.6 \pm 3.6 \mathrm{mg} / \mathrm{kg}$ of nicotine during 36 training sessions, and exhibited stable operant behavior ( $\pm 10 \%$ for three consecutive sessions) before microdialysis testing. The YA group $(n=9)$ received
$49.2 \pm 3.7 \mathrm{mg} / \mathrm{kg}$ of nicotine over the same number of sessions. During the microdialysis test session, the SA group consumed $1.6 \pm 0.3 \mathrm{mg} / \mathrm{kg}$ nicotine and the YA and Acute $(n=9)$ groups each received $1.6 \pm 0.3 \mathrm{mg} / \mathrm{kg}$ nicotine following infusion patterns identical to their paired SA counterparts. The apparent difference in exposure between these groups is related to the differential group sizes.

The experimental design allowed evaluation of the effects of prior nicotine exposure on baseline dialysate lipid levels collected in a nicotine-free state (approximately $48 \mathrm{~h}$ after the previous nicotine exposure). There were no significant effects of prior nicotine exposure (either SA or YA) on baseline levels of 2-AG $\left(\mathrm{F}_{(2,29)}=0.910\right.$; Figure 1a), $\operatorname{AEA}\left(\mathrm{F}_{(2,27)}=0.892\right.$; Figure $2 \mathrm{a})$, or PEA $\left(\mathrm{F}_{(2,28)}=0.924\right.$; Figure $\left.4 \mathrm{~d}\right)$ as compared with levels of these analytes observed in nicotine-naïve rats (eg, the Acute group baseline before nicotine exposure). In contrast, prior nicotine SA experience resulted in reduced baseline dialysate OEA levels $(p<0.05)$ relative to nicotinenaïve controls $\left(\mathrm{F}_{(2,29)}=3.670, p<0.05\right.$; Figure $\left.4 \mathrm{a}\right)$. While OEA levels trended downward in the YA group, this did not reach statistical significance.

Subsequent nicotine administration significantly increased in VTA dialysate 2-AG content in all groups as determined by repeated-measures ANOVA (Acute $\left(\mathrm{F}_{(8,104)}=2.519, p<0.005\right) ; \mathrm{YA}\left(\mathrm{F}_{(4,52)}=2.020, p<0.05\right)$; $\mathrm{SA}$ $\left(\mathrm{F}_{(6,78)}=1.891, p<0.05\right.$; Figure $\left.1 \mathrm{~b}\right)$. Comparison of the Acute and YA groups revealed an effect of nicotine $\left(\mathrm{F}_{(1,13)}=3.825, p<0.001\right)$ and drug history $\left(\mathrm{F}_{(1,13)}=7.668\right.$, $p<0.05)$, as well as an interaction between these factors $\left(\mathrm{F}_{(13,143)}=2.752, p<0.005\right)$. Comparison of $\mathrm{SA}$ and $\mathrm{YA}$ groups revealed an effect of nicotine $\left(\mathrm{F}_{(1,13)}=3.886\right.$, $p<0.001)$, but no significant effect of response contingency $\left(\mathrm{F}_{(1,13)}=0.993\right.$, NS $)$ or interaction between these factors $\left(\mathrm{F}_{(8,143)}=1.263\right.$, NS). Thus, although prior drug history significantly alters nicotine-induced increases in VTA 2-AG levels, the volitional nature of repeated drug exposure does not significantly influence nicotine-induced increases in VTA 2-AG. However, no significant group differences were evident on comparison of composite AUC indices of the nicotine administration period (Figure 1c).

Nicotine administration produced distinct effects on VTA dialysate AEA content according to both drug history and response contingency (Figure $2 \mathrm{~b}$ ). Based on repeatedmeasures ANOVA, forced nicotine administration significantly decreased dialysate AEA in the Acute group $\left(\mathrm{F}_{(5,65)}=4.298, p<0.001\right)$, although no changes in dialysate AEA were evident in the YA group $\left(\mathrm{F}_{(6,78)}=0.953\right.$, NS). Although no effect of drug history was evident on comparison of composite AUC measures of the Acute and YA groups (Figure 2c), two-way repeated-measures ANOVA revealed a significant interaction between drug history and nicotine effects $\left(\mathrm{F}_{(13,143)}=2.441, p<0.01\right)$. Comparison of effects in the YA and SA groups that had an identical history of nicotine exposure revealed a significant influence of response contingency. In contrast to the lack of nicotine effects in the YA group, dialysate AEA levels were significantly increased by nicotine $\mathrm{SA} \quad\left(\mathrm{F}_{(10,130)}=2.109\right.$, $p<0.05)$, and two-way ANOVA revealed a significant interaction between response contingency and nicotine effects $\left(\mathrm{F}_{(13,208)}=2.441, p<0.05\right)$. This distinction was further validated by a significantly greater composite AUC value in the SA vs YA group $\left(\mathrm{F}_{(1,19)}=4.770, p<0.05\right)$. 

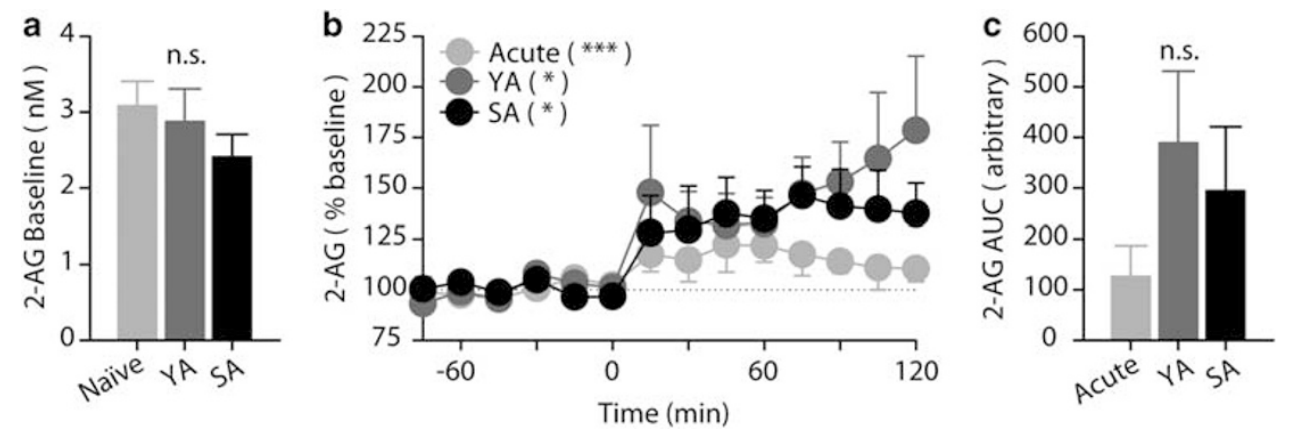

Figure I Effects of volitional nicotine self-administration (SA) and forced nicotine yoked administration (YA) on dialysate 2-arachidonoyl glycerol (2-AG) levels collected from the rat ventral tegmental area (VTA). For evaluation of the effects of repeated nicotine exposure, a comparative group receiving noncontingent YA for the first time (Acute) was also presented. The SA $(n=12)$ group lever pressed for nicotine infusions during the session, while the $Y A$ $(n=\mid \mathrm{I})$ and Acute $(n=9)$ groups received response-independent nicotine infusions following a temporal pattern tied to the SA group (eg, YA design). There were no significant effects of prior nicotine exposure on baseline 2-AG levels, regardless of response contingency (a). Intravenous nicotine delivery significantly increased dialysate 2-AG levels in all groups, regardless of response contingency or prior history with the drug (b (temporal profile) and c (total response indexed by area under the curve (AUC))). Significance for baseline and AUC was determined by analysis of variance (ANOVA) followed by Fisher's protected least significant difference (PLSD) $(* p<0.05$, $* * p<0.01$, and $* * * *<0.00 \mathrm{I})$. Significance for group effects of time was determined by

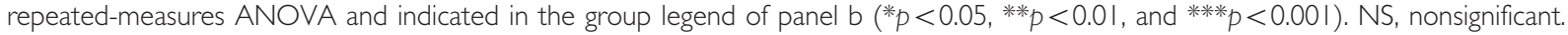
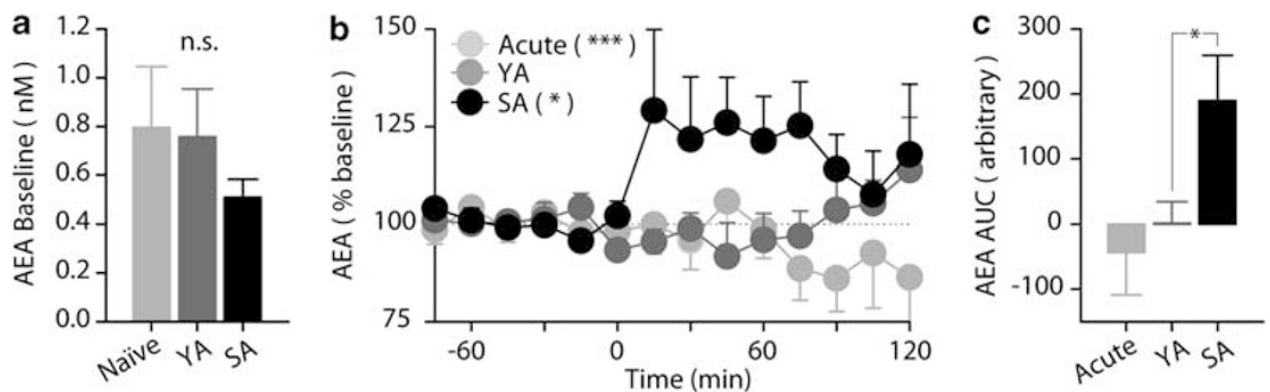

Figure 2 Effects of volitional nicotine self-administration (SA) vs forced nicotine yoked administration (YA) on ventral tegmental area (VTA) dialysate anandamide (AEA) levels. Effects of repeated nicotine exposure are indexed by comparison of AEA responses to Acute vs repeated (YA) non-contingent nicotine exposure. There were no significant effects of prior nicotine exposure on baseline AEA levels, regardless of response contingency (a). Volitional nicotine SA $(n=12)$ significantly increased dialysate AEA levels, although response-independent nicotine infusions did not alter dialysate AEA in YA animals $(n=11)$. Drug-naïve animals receiving nicotine for the first time (Acute; $n=9)$ displayed reduced AEA levels following nicotine exposure $(b$ and $c)$. Statistical evaluations and levels of significance are as described in the legend for Figure I. NS, nonsignificant.

Nicotine did not significantly alter VTA dialysate levels of either OEA or PEA during the exposure session under any of the conditions evaluated. Specifically, for OEA (Figure $3 \mathrm{~b}$ ) there were no significant effects of drug history (Acute vs YA: history $\left(\mathrm{F}_{(1,9)}=0.024, \mathrm{NS}\right)$; nicotine $\left(\mathrm{F}_{(1,13)}=0.430, \mathrm{NS}\right)$; and interaction $\left.\left(\mathrm{F}_{(13,117)}=0.363, \mathrm{NS}\right)\right)$ or response contingency (YA vs SA: contingency $\left(\mathrm{F}_{(1,13)}=1.602, \mathrm{NS}\right)$; nicotine $\left(\mathrm{F}_{(1,13)}=1.660, \mathrm{NS}\right) ;$ and interaction $\left.\left(\mathrm{F}_{(13,169)}=0.628, \mathrm{NS}\right)\right)$. It is worth noting that the significantly lower baseline OEA levels in the SA group amplifies the apparent effect of nicotine when expressed as the percent change from baseline (Figure 3b). When considered as the change in absolute dialysate concentration, nicotine YA and SA produce nearly identical profiles (not shown). Analyses of nicotine-induced alterations in dialysate OEA fail to reach significance, regardless of the analysis by either the change in absolute concentration or the percent change from pre-nicotine baseline. For PEA (Figure 3e), there were no significant effects of drug history (Acute vs YA: history $\left(\mathrm{F}_{(1,12)}=0.017\right.$, NS); nicotine $\left(\mathrm{F}_{(1,13)}=1.513, \mathrm{NS}\right)$; and interaction $\left.\left(\mathrm{F}_{(13,156)}=0.559, \mathrm{NS}\right)\right)$ or response contingency (YA vs SA: contingency $\left(\mathrm{F}_{(1,15)}\right.$ $=0.228, \mathrm{NS})$; nicotine $\left(\mathrm{F}_{(1,13)}=1.202, \mathrm{NS}\right)$; and interaction $\left.\left(\mathrm{F}_{(13,195)}=1.140, \mathrm{NS}\right)\right)$. Similarly, no group differences were evident on comparison of composite AUC indices of OEA or PEA effects during the nicotine administration period (Figure $3 e$ and $\mathrm{f}$, respectively).

\section{Effect of Volitional (SA) vs Forced (YA) Nicotine Exposure on eCB, Ethanolamide, and NA-NT Levels in Regional Brain Tissue Samples}

Rats in the SA group $(n=14)$ acquired stable levels of nicotine intake within 8 training sessions and received a total of $16.0 \pm 1.6 \mathrm{mg} / \mathrm{kg}$ of nicotine over 17 sessions of drug training; $0.66 \pm 0.06 \mathrm{mg} / \mathrm{kg}$ nicotine was consumed during the final session before being killed. Animals in the YA group $(n=10)$ received $16.6 \pm 1.8 \mathrm{mg} / \mathrm{kg}$ of nicotine over the course of the 17 sessions and $0.68 \pm 0.06 \mathrm{mg} / \mathrm{kg}$ during the final session.

Chronic intravenous nicotine exposure increased VTA tissue AEA content without altering VTA 2-AG or ethanolamide content (Figure 4a). Specifically, VTA AEA content was higher in nicotine-exposed animals with slightly higher increases evident in the YA $(p<0.001 v s$ naïve) $v s$ the SA $(p<0.01$ vs naïve, $p<0.01$ vs YA) groups. No detectable group differences were evident for OEA, PEA, or 2-AG content in VTA tissue (Figure $4 \mathrm{~b}-\mathrm{d}$ ). With regard to the 

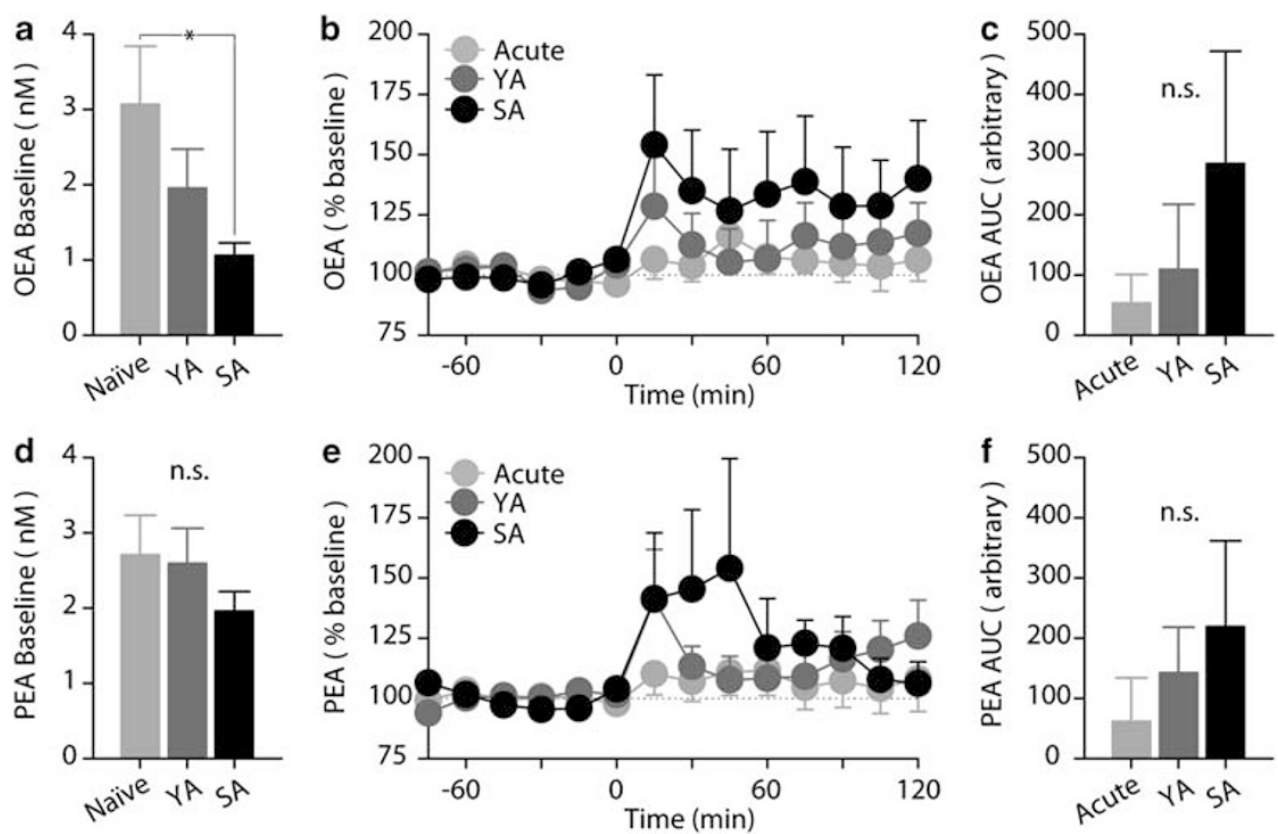

Figure 3 Effects of volitional nicotine self-administration (SA) vs forced nicotine yoked administration (YA) on ventral tegmental area (VTA) dialysate oleyolethanolamide (OEA) and palmitoylethanolamide (PEA) levels. Effects of repeated nicotine exposure are indexed by comparison of OEA responses to Acute vs repeated (YA) non-contingent nicotine exposure. Baseline OEA levels were significantly lower in VTA dialysates from animals with a history of nicotine SA ( $n=12)$ as compared with nicotine-naïve controls $(n=9 ;$ a). Baseline OEA levels in rats with a history of forced nicotine exposure (YA; $n=1 \mathrm{I})$ also tended to be lower than controls, although this did not reach significance. Dialysate OEA content was unaltered during nicotine exposure, regardless of drug history or response contingency (b and $c)$. There was no significant effect of prior nicotine exposure on baseline PEA levels, regardless of response contingency (d). Dialysate PEA content was unaltered during nicotine exposure, regardless of drug history or response contingency (e and f). Statistical evaluations and levels of significance are as described in the legend for Figure I. NS, nonsignificant.

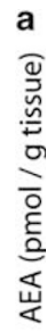
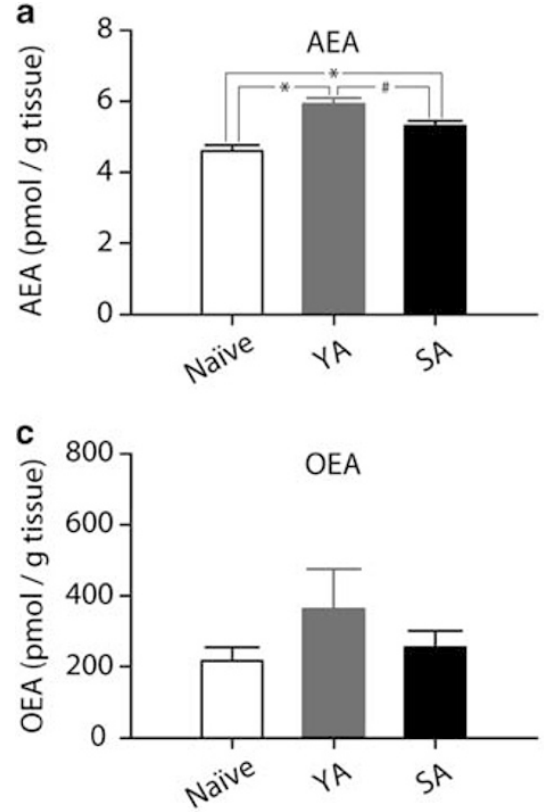

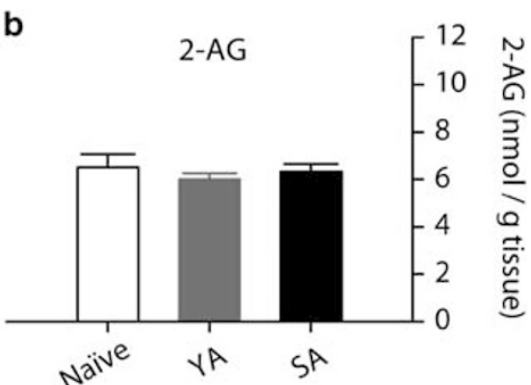

d

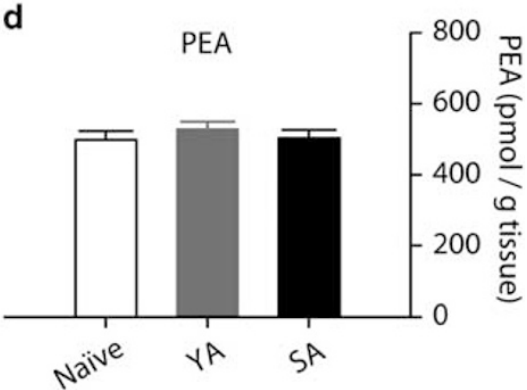

Figure 4 Effects of volitional (self-administration (SA); $n=14$ ) and forced (yoked administration $(Y A) ; n=12$ ) nicotine exposure on ventral tegmental area (VTA) tissue (a) anandamide (AEA), (b) 2-arachidonoyl glycerol (2-AG), (c) oleyolethanolamide (OEA), and (d) palmitoylethanolamide (PEA) content as compared with levels of these analytes in VTA tissue of nicotine-naive controls (indexed by lipid extracts from bulk tissue quantified by liquid chromatography-tandem mass spectrometry (LC-MS/MS)). VTA AEA content was significantly increased by both volitional (SA) and forced (YA) nicotine exposure relative to levels in drug-naïve controls $(n=10)$, although YA exposure resulted in significantly greater increases than SA exposure. No significant nicotine-related changes in 2-AG, OEA, or PEA levels were evident in either SA or YA groups relative to drug-naive controls. Significance was determined by analysis of variance (ANOVA) followed by a single false discovery rate analysis (vs control ${ }^{*} p<0.05$, vs SA ${ }^{*} p<0.05$ ). 

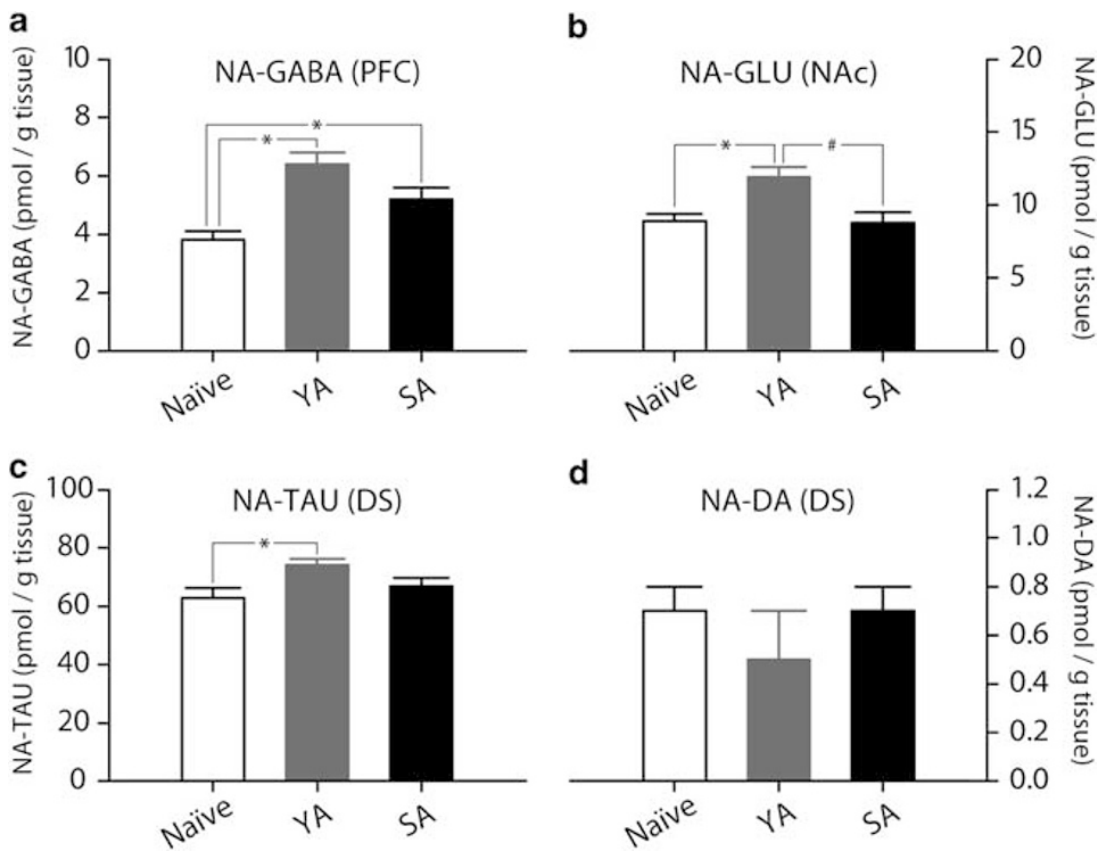

Figure 5 Effects of volitional (self-administration $(S A) ; n=14$ ) and forced (yoked administration $(Y A) ; n=12$ ) nicotine exposure on regional brain tissue $n$-arachidonoyl conjugates of neurotransmitters (NA-NT) content as compared with levels of these analytes in nicotine-naive controls (indexed by lipid extracts from bulk tissue quantified by liquid chromatography-tandem mass spectrometry (LC-MS/MS)). (a) Prefrontal cortex (PFC) NA- $\gamma$-aminobutyric acid (GABA) content was significantly increased by both volitional $(S A)$ and forced $(Y A)$ nicotine exposure relative to levels in drug-naïve controls $(n=10)$, although YA exposure resulted in significantly greater increases than SA exposure. (b) Nucleus accumbens (NAc) NA-glutamate (GLU) and (c) dorsal striatum (DS) NA-taurine (TAU) content were significantly increased by YA nicotine exposure relative to levels in drug-naive controls. No significant nicotine-related changes of DS NA-DA levels were evident in either SA or YA groups relative to drug-naïve controls (d). Significance was determined by analysis of variance (ANOVA) followed by a single false discovery rate analysis (vs control $* p<0.05$, vs SA ${ }^{\#} p<0.05$ ).

other brain regions evaluated, YA generally produced greater increases in AEA content than SA did (Table 1). For example, nicotine-induced increases in tissue AEA content in the NAc $(p<0.001)$, SNr $(p<0.05)$, PFC $(p<0.01)$, and AMYG $(p<0.01)$ were solely attributable to the YA group. In fact, YA increased SNr AEA content by nearly fivefold, the largest recorded change in this experiment, yet no corresponding alteration occurred in the SA group.

Interestingly, chronic nicotine exposure altered bulk tissue levels of a number of NA-NTs (Figure 5). Levels of NA-GABA increased in the PFC following both SA $(p<0.01)$ and YA $(p<0.001)$. In contrast, while nicotine SA was not associated with alterations in NA-GLU or NA-TAU, nicotine YA increased NA-GLU in the NAc $(p<0.01)$ and $\mathrm{SNr}$ $(p<0.01)$, as well as NA-TAU in the DS $(p<0.01)$ and SNr $(p<0.001)$. NA-DA was detected exclusively in the DS, but chronic nicotine exposure did not alter bulk tissue levels. Each of the seven brain regions in this study exhibited a unique profile of changes in at least one of the nine lipid species identified in bulk tissue, as illustrated in the complete data set from this experiment (Table 1).

\section{Effect of Nicotine Exposure on FAAH Activity in the VTA}

Following the microdialysis session, a representative subset of rats from the SA group $(51.3 \pm 2.8 \mathrm{mg} / \mathrm{kg}$ of total nicotine history), YA group $(51.3 \pm 3.1 \mathrm{mg} / \mathrm{kg}$ of total nicotine history), and Acute group ( $1.6 \pm 0.3 \mathrm{mg} / \mathrm{kg}$ nicotine) were analyzed for FAAH activity in the VTA. Endogenous FAAH activity in the VTA from drug-naïve rats produced $1770 \pm 200 \mathrm{pmol} / \mathrm{mg}$ of tissue, comparable to previous work measuring FAAH activity in the AMYG (Hill et al, 2009). Relative to drug-naïve animals $(100 \pm 11 \%, n=7)$, there was no significant effect of nicotine in any of the Acute $(108 \pm 9 \%, n=7)$, YA $(90 \pm 8 \%, n=6)$, or SA $(99 \pm 14 \%$, $n=7$ ) exposure groups as determined by ANOVA.

\section{DISCUSSION}

The present observations highlight the independent regulation of 2-AG, AEA, and OEA levels in the VTA in response to nicotine administration, consistent with prior reports of differential alterations in interstitial 2-AG and AEA by other drugs of abuse (Alvarez-Jaimes et al, 2009; Caille et al, 2007). The data also reveal distinct influences of nicotine SA $v s$ forced nicotine administration on interstitial AEA and OEA levels and underscore the differences between in vivo microdialysis and post-mortem tissue extractions for indexing levels of neuroactive lipids in the brain.

\section{Functional Implications of Distinct Nicotine-Induced Effects on 2-AG, AEA, and OEA}

Nicotine increased VTA dialysate 2-AG levels under every administration condition evaluated (Acute, YA, and SA). This consequence of nicotine exposure may be of substantial import as 2-AG has a key role in the plasticity of GLU signaling onto VTA DA neurons (Haj-Dahmane and 
Table I Effects of Volitional (SA) and Forced (YA) Nicotine Exposure on Regional Brain eCB Content as Measured from Lipid Extracts from Bulk Tissues by LC-MS/MS

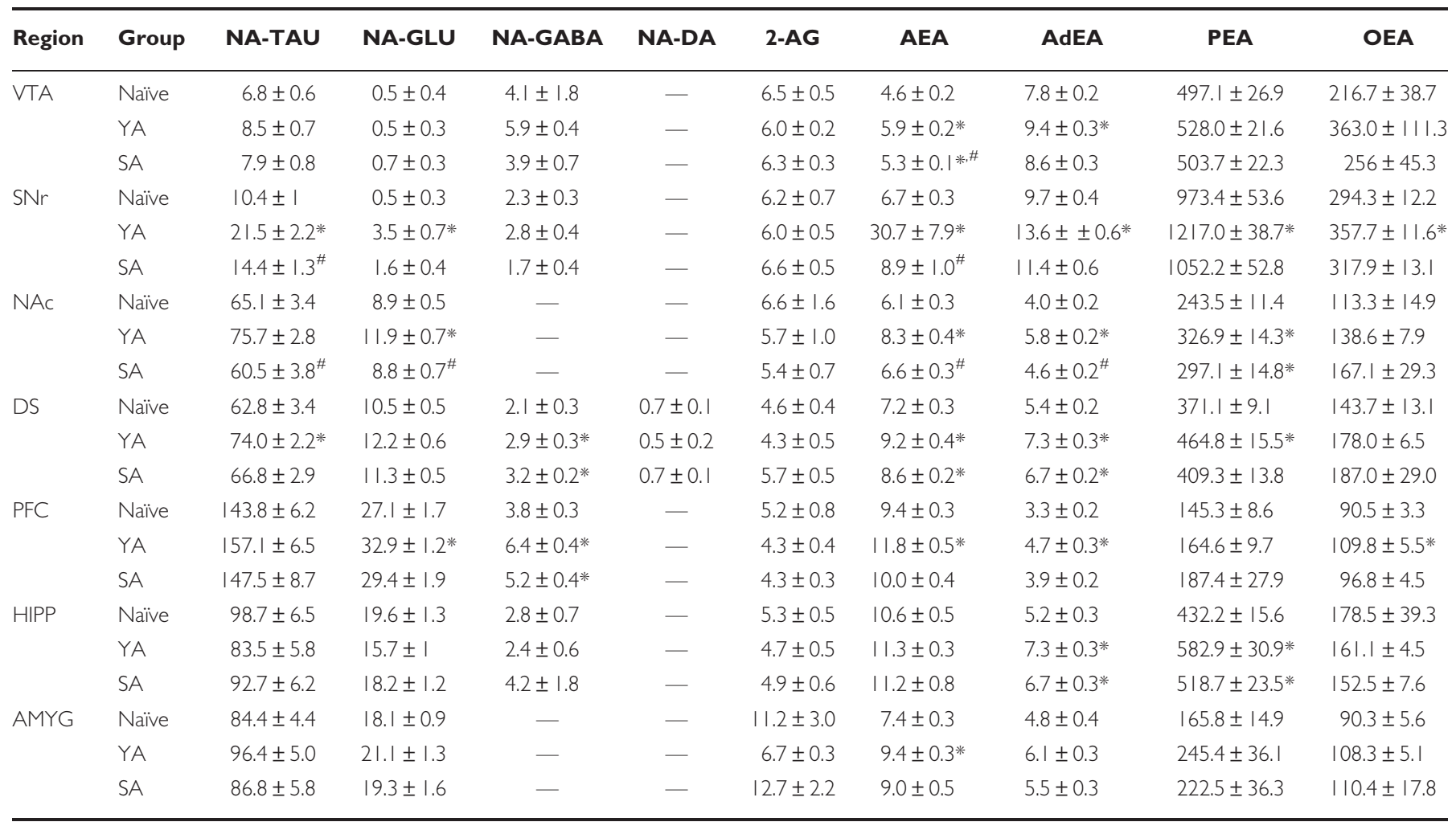

All lipids expressed as pmol/g, except 2-AG (nmol/g); not detected was indicated by -; vs naïve ${ }^{*} p<0.05$, vs YA ${ }^{\#} p<0.05 ;$ naïve $(n=10)$, YA $(n=12), S A(n=14)$.

Shen, 2010; Kortleven et al, 2011), which is thought to be a critical component of tobacco addiction (Mansvelder et al, 2009). Moreover, increased 2-AG signaling in the VTA potentiates cue-evoked increases in the NAc DA and associated reward-seeking (Oleson et al, 2012), and this may participate in the well-known enhancement of cue conditioning that contributes to nicotine reward (Caggiula et al, 2002; Chaudhri et al, 2006). Nicotine-induced elevations in VTA 2-AG were enhanced following repeated drug exposure, and no differences were evident in the 2-AG response to nicotine SA vs YA. This is consistent with a 2AG involvement in nicotine-induced VTA synaptic plasticity and enhancement of cue conditioning as both of these processes increase with repeated nicotine exposure with comparable effects being evident following either SA or forced nicotine administration.

Nicotine SA induced significant increases in dialysate AEA content, although no change in AEA levels were evident during nicotine YA. Relatively little is known regarding the influence of AEA signaling on VTA neurophysiology. Increased VTA AEA signaling may enhance DA cell activity through at least two mechanisms, including $\mathrm{CB}_{1}$-mediated decreases in presynaptic GABA release (Lupica and Riegel, 2005; Szabo et al, 2002) and increased GLU release via activation of transient receptor potential vanilloid $1\left(\mathrm{TRPV}_{1}\right)$ receptors on glutamatergic terminals (Marinelli et al, 2005). In contrast, $\mathrm{CB}_{1}$-mediated suppression of VTA GLU release has also been reported (Lupica et al, 2005; Melis et al, 2004), and this may contribute to the reported $\mathrm{CB}_{1}$-mediated attenuation of nicotine-induced excitation of VTA DA cells evident following FAAH inhibition (Melis et al, 2008). It is presently unclear which of these mechanisms prevails in propagating AEA signaling during nicotine SA.

Nicotine SA, but not YA, resulted in selective deficits in baseline interstitial OEA levels in the VTA, implicating the volitional nature of drug intake on this effect. Although OEA has no significant activity in the $\mathrm{CB}_{1}$ receptors, it strongly activates peroxisome proliferator-activated receptor $\alpha\left(\mathrm{PPAR}_{\alpha}\right)$ signaling in vivo (Fu et al, 2003). $\mathrm{PPAR}_{\alpha}$ activation by OEA and other agonists reduces nicotine SA, prevents nicotine-induced increases in VTA DA cell burst firing, and attenuates nicotine-induced increases in NAc DA release (Mascia et al, 2010, 2011; Melis et al, 2008). $\mathrm{PPAR}_{\alpha}$ receptors can exert tonic inhibition of DA cell activity, as their antagonism increases the spontaneous firing rate of VTA DA neurons (Melis et al, 2010). Accordingly, deficient OEA tone may contribute to enhanced spontaneous firing and burst activity of VTA DA cells that is more pronounced following a history of nicotine SA vs YA (Caille et al, 2009). The PPAR ${ }_{\alpha}$ influence on VTA DA cell activity likely occurs through a negative modulation of $\alpha_{4} \beta_{2}$-nACh receptor expression or function (Melis et al, 2010), and it is conceivable that reduced $\mathrm{PPAR}_{\alpha}$ activation resulting from deficient OEA tone contributes to enhanced VTA $\alpha_{4} \beta_{2^{-}}$ $\mathrm{nACh}$ receptor expression that is more pronounced following nicotine SA vs YA (Metaxas et al, 2010). Although nicotine SA produced subtle nonsignificant elevations in dialysate OEA content, this was not sufficient to restore OEA to levels observed in nicotine-naïve controls. 
The present findings provide additional indication of the complex influence of cannabinoid and ethanolamide signaling on nicotine-taking and nicotine-seeking behaviors. For example, although synthetic $\mathrm{CB}_{1}$ agonists increase nicotine SA and enhance nicotine-seeking behavior (Gamaleddin et al, 2012), these nicotine-related behaviors are generally attenuated by enhancing endogenous $\mathrm{eCB}$ tone (eg, eCB clearance inhibition) (Forget et al, 2009; Gamaleddin et al, 2011; Scherma et al, 2008). The distinction between these influences may arise, in part, from differential regional patterns of $\mathrm{CB} 1$ activation. While exogenous agonists induce widespread $\mathrm{CB}_{1}$ activation, eCB clearance inhibition likely results in regionally restricted $\mathrm{CB}_{1}$ activation created by region-specific differences in nicotine-induced $\mathrm{eCB}$ formation and/or $\mathrm{eCB}$ modulations induced by nicotine-seeking. Moreover, in contrast to $\mathrm{CB}_{1}$ selective agonists, manipulations such as FAAH inhibition also enhance signaling through non-CB receptors $\left(\mathrm{PPAR}_{\alpha}\right.$, $\mathrm{TRPV}_{1}$, and so on) that may counter or modify the effects of concurrent $\mathrm{CB}_{1}$ receptor signaling. Because the nature of nicotine-induced alterations in $\mathrm{eCB}$ signaling may differ at various stages of nicotine exposure (eg, acquisition $v s$ maintenance of drug intake; dependence), and nicotineinduced eCB alterations may differ from eCB disruptions associated with nicotine-seeking behavior (induced by cues, drug priming, and/or stress), it is not surprising that the influence of $\mathrm{eCB}$ clearance inhibition on nicotine-related behaviors varies among these distinct phases of nicotine use (Forget et al, 2009; Scherma et al, 2008).

\section{Potential Mechanisms for the Distinct Influence of Nicotine SA and YA on VTA eCBs}

As described above, we find that a history of volitional nicotine SA exerts greater effects on basal OEA levels as compared with forced nicotine YA. In a somewhat similar manner, we find that VTA AEA levels are more potently increased by nicotine SA vs YA (which did not alter dialysate AEA). Tendencies toward greater effects of nicotine SA $v s$ YA on dialysate OEA and PEA were also evident, although this did not reach significance. In contrast, dialysate 2-AG levels were enhanced during both SA and YA (compared with Acute exposure) and there were no significant between-group differences in this effect. Because AEA, OEA, and PEA are degraded through a common mechanism (FAAH), while 2-AG is degraded through a distinct route (hydrolysis by monoacylglycerol lipase, MAGL), it could be argued that FAAH and MAGL activities are differentially influenced by the volitional nature of nicotine administration. However, we found no significant differences in FAAH activity in VTA tissue from animals in the SA, YA, or Acute groups as compared with nicotine-naïve controls. Moreover, because FAAH exerts comparable hydrolytic activity on AEA, OEA, and PEA, the data demonstrating an independent regulation of these ethanolamides argues against a substantial influence of SA$v s$ YA-induced disruptions in FAAH activity.

Alternately, volitional $v s$ forced nicotine administration may differentially influence the mechanisms contributing to the formation of AEA and related ethanolamides. Unfortunately, several limitations hinder the ability to probe for group-related differences in AEA biosynthesis. For example, the pathway(s) for AEA synthesis have not been unequivocally identified (Leung et al, 2006; Simon and Cravatt, 2008; Liu et al, 2008), and there are presently no selective inhibitors available for any of the enzymes implicated in AEA biosynthesis. The volitional nature of nicotine exposure may also influence the neurochemical stimuli that provoke AEA production. For example, nicotine SA and YA produce distinct alterations in $\mathrm{nAChR}$ expression, DA $\mathrm{D}_{2}$ receptor binding, and corticosterone levels (Caille et al, 2009; Donny et al, 2000; Metaxas et al, 2010), and each of these systems can influence the production of AEA and related ethanolamides (Centonze et al, 2004; Di et al, 2003, 2005; Giuffrida et al, 1999; Hill et al, 2010a, b; Stella and Piomelli, 2001).

Further work is needed to characterize which, if any, of these neurochemical mechanisms underlie the distinct effects of nicotine SA and YA on AEA and related ethanolamides. Extensive evidence implicates $\mathrm{mGluR}_{5}$ and other postsynaptic $\mathrm{G}_{\mathrm{q}}$-coupled receptors in the activation of diacylglycerol lipase $\alpha$ involved in 2-AG formation (Jung et al, 2005), although the relative influence of volitional $v s$ forced nicotine administration on these and related $\mathrm{G}_{\mathrm{q}^{-}}$ coupled receptors have not been investigated. It is conceivable, however, that diminished 2-AG formation has a role in the attenuation of nicotine SA behavior induced by mGluR $_{5}$ antagonists (D'Souza and Markou, 2011; Tronci and Balfour, 2011).

\section{The Volitional Nature of Nicotine Exposure also Influences Brain Bulk Tissue Lipids}

Consistent with the microdialysis results discussed above, nicotine SA and YA were found to induce distinct effects on eCB levels extracted from post-mortem brain tissue. Similar to the microdialysis results, the distinction between the effects of SA and YA was evident in measures of tissue AEA, but not 2-AG, OEA, or PEA. The differential influence of SA vs YA on tissue AEA levels was present in VTA, as well as the $\mathrm{SNr}$ and NAc. In contrast to the microdialysis results, nicotine YA induced greater increases in tissue AEA than nicotine SA; this was evident in the VTA, SNc, and NAc, with similar trends observed in the DS and PFC. In further contrast to the microdialysis results, no effect of nicotine administration on tissue 2-AG content was evident in any region evaluated, regardless of the nature of nicotine exposure (eg, SA vs YA). Although animals in the tissue extraction study received less total nicotine exposure than their counterparts in the microdialysis study, the significant effect of nicotine on dialysate 2-AG during the first nicotine exposure suggests that differences in nicotine history do not explain the disparity between the microdialysis and tissue extraction studies.

Several distinctions between these eCB sampling techniques may contribute to the dissimilar profiles provided by in vivo microdialysis and post-mortem brain tissue lipid extraction procedures (Buczynski et al, 2010). For example, robust post-mortal increases in brain tissue AEA and 2-AG content have been shown to occur even within $30 \mathrm{~s}$ of death (see Buczynski and Parsons (2010) for discussion), and this may be related to or exacerbated by several factors, including the stress and ischemia associated with $\mathrm{CO}_{2}$ euthanasia. These effects may interact with processes 
engaged by the pre-euthanasia manipulation (nicotine exposure itself and possible stress associated with removal from the nicotine-exposure chamber) to distort the perceived effects of the manipulation. Subtle nicotineinduced alterations in neuronally derived $\mathrm{eCB}$ or ethanolamide production may also be overshadowed by post-mortal lipid accumulation and/or the contribution of non-neuronal eCB and ethanolamide sources that are unavoidably indexed by tissue extraction procedures. This latter possibility may explain the lack of evidence for nicotineinduced alterations in brain 2-AG levels in the tissue extraction experiment. These issues highlight an important advantage of in vivo microdialysis wherein brain eCB levels are monitored in awake and freely moving animals. Nonetheless, brain tissue analysis allow for rapid characterization of region-specific alterations in $\mathrm{eCB}$ content and provide an index of manipulation-induced alterations in eCB production (with acknowledgment of the caveats discussed above). In this regard, the present tissue data reinforce the conclusion that the nature of nicotine exposure (SA vs YA) can differentially influence brain eCB levels and provide evidence for nicotine-induced disruptions eCB, ethanolamide, and as discussed below NA-NT levels in the VTA and other regions of the mesocorticolimbic system.

Although a role for NA-NTs in drug-related behavior has not been established, the present data demonstrate robust, regionally distinct alterations in brain tissue NA-NT content following chronic nicotine exposure, including alterations in NA-GLU, NA-GABA, and NA-TAU. Recent studies suggest that some NA-NTs such as NA-DA originate from the direct conjugation of the parent transmitter to arachidonic acid (Hu et al, 2009). A common biosynthetic mechanism could suggest that regional levels depend on the relative amount of available NT. In support of this notion, we find that NA-TAU and NA-GLU exhibit a 100 -fold range in regional levels, and detectable levels of NA-DA were present only in the DS. This contrasts with relatively stable levels of AEA and 2-AG content, which vary $<2$-fold across brain regions. As a class, NA-NTs are considered as potential ligands for T-type calcium channels (Barbara et al, 2009; Ross et al, 2009), TRP receptors (Saghatelian et al, 2006), and GPCRs (Bradshaw et al, 2009). To this end, identifying their endogenous target receptors and assessment of their signaling competent levels by microdialysis represent important objectives. Indeed, based on their susceptibility to nicotine exposure and their regional disparity, they represent an interesting area for future research.

In conclusion, the present results demonstrate that nicotine differentially modulates brain levels of 2-AG, $\mathrm{AEA}$, and OEA, and that the nature of these modulations can be influenced by the volitional nature of the drug exposure. As indexed by VTA microdialysis, nicotine SA induced greater decrements in baseline OEA levels and greater drug-induced increases in AEA levels than did forced YA. Each of these effects may contribute to enhanced activity and excitability of VTA DA neurons evident following chronic self-administered, but not forced, nicotine exposure (Caille et al, 2009; Metaxas et al, 2010), an effect that likely enhances both the direct and conditioned reinforcing effects of the drug. The present data also demonstrate that nicotine-induced increases in VTA 2-AG levels are influenced by drug history, but not by response contingency. Nicotine-induced increases in 2-AG signaling may contribute to $\mathrm{CB}_{1}$-mediated synaptic plasticity and conditioning effects that have an important role in tobacco dependence but are not influenced the volitional nature of nicotine exposure. Collectively, these findings highlight the independent regulation of 2-AG, AEA, and OEA signaling in the brain and underscore the importance of incorporating volitional control of drug intake in the characterization of drug-induced alterations in eCB signaling.

\section{ACKNOWLEDGEMENTS}

This is manuscript number 21701 from The Scripps Research Institute. We thank Dr Jonathan Z Long and Ryan B Lamer for the synthesis and purification of $n$ arachidonoyl GLU, Dr Benjamin F Cravatt for access to mass spectrometry instrumentation, and Dr Nimish Sidhpura for helpful discussions and assistance in preparing the manuscript. This work was supported by NIDA Grants P01 DA017259 (LHP) and F32 DA029994 (MWB).

\section{DISCLOSURE}

The authors declare no conflict of interest.

\section{REFERENCES}

Alvarez-Jaimes L, Stouffer DG, Parsons LH (2009). Chronic ethanol treatment potentiates ethanol-induced increases in interstitial nucleus accumbens endocannabinoid levels in rats. J Neurochem 111: 37-48.

Barbara G, Alloui A, Nargeot J, Lory P, Eschalier A, Bourinet E et al (2009). T-type calcium channel inhibition underlies the analgesic effects of the endogenous lipoamino acids. J Neurosci 29: 13106-13114.

Bradshaw HB, Lee SH, McHugh D (2009). Orphan endogenous lipids and orphan GPCRs: a good match. Prostaglandins Other Lipid Mediat 89: 131-134.

Buczynski MW, Parsons LH (2010). Quantification of brain endocannabinoid levels: methods, interpretations and pitfalls. Br J Pharmacol 160: 423-442.

Caggiula AR, Donny EC, Chaudhri N, Perkins KA, Evans-Martin FF, Sved AF (2002). Importance of nonpharmacological factors in nicotine self-administration. Physiol Behav 77: 683-687.

Caille S, Alvarez-Jaimes L, Polis I, Stouffer DG, Parsons LH (2007). Specific alterations of extracellular endocannabinoid levels in the nucleus accumbens by ethanol, heroin, and cocaine selfadministration. J Neurosci 27: 3695-3702.

Caille S, Guillem K, Cador M, Manzoni O, Georges F (2009). Voluntary nicotine consumption triggers in vivo potentiation of cortical excitatory drives to midbrain dopaminergic neurons. J Neurosci 29: 10410-10415.

Centonze D, Battista N, Rossi S, Mercuri NB, Finazzi-Agro A, Bernardi $G$ et al (2004). A critical interaction between dopamine D2 receptors and endocannabinoids mediates the effects of cocaine on striatal gabaergic Transmission. Neuropsychopharmacology 29: 1488-1497.

Chang JY, Sawyer SF, Lee RS, Woodward DJ (1994). Electrophysiological and pharmacological evidence for the role of the nucleus accumbens in cocaine self-administration in freely moving rats. J Neurosci 14(Part 1): 1224-1244. 
Chaudhri N, Caggiula AR, Donny EC, Palmatier MI, Liu X, Sved AF (2006). Complex interactions between nicotine and nonpharmacological stimuli reveal multiple roles for nicotine in reinforcement. Psychopharmacology (Berl) 184: 353-366.

Cheer JF, Wassum KM, Sombers LA, Heien ML, Ariansen JL, Aragona BJ et al (2007). Phasic dopamine release evoked by abused substances requires cannabinoid receptor activation. J Neurosci 27: 791-795.

Chen X, Williamson VS, An SS, Hettema JM, Aggen SH, Neale MC et al (2008). Cannabinoid receptor 1 gene association with nicotine dependence. Arch Gen Psychiatry 65: 816-824.

Cohen C, Kodas E, Griebel G (2005). CB1 receptor antagonists for the treatment of nicotine addiction. Pharmacol Biochem Behav 81: 387-395.

Cohen C, Perrault G, Voltz C, Steinberg R, Soubrie P (2002). SR141716, a central cannabinoid $(\mathrm{CB}(1))$ receptor antagonist, blocks the motivational and dopamine-releasing effects of nicotine in rats. Behav Pharmacol 13: 451-463.

D'Souza MS, Markou A (2011). Metabotropic glutamate receptor 5 antagonist 2-methyl-6-(phenylethynyl)pyridine (MPEP) microinfusions into the nucleus accumbens shell or ventral tegmental area attenuate the reinforcing effects of nicotine in rats. Neuropharmacology 61: 1399-1405.

Di Ciano P, Blaha CD, Phillips AG (1996). Changes in dopamine oxidation currents in the nucleus accumbens during unlimitedaccess self-administration of d-amphetamine by rats. Behav Pharmacol 7: 714-729.

Di S, Malcher-Lopes R, Halmos KC, Tasker JG (2003). Nongenomic glucocorticoid inhibition via endocannabinoid release in the hypothalamus: a fast feedback mechanism. J Neurosci 23: 4850-4857.

Di S, Malcher-Lopes R, Marcheselli VL, Bazan NG, Tasker JG (2005). Rapid glucocorticoid-mediated endocannabinoid release and opposing regulation of glutamate and gamma-aminobutyric acid inputs to hypothalamic magnocellular neurons. Endocrinology 146: 4292-4301.

Donny EC, Caggiula AR, Rose C, Jacobs KS, Mielke MM, Sved AF (2000). Differential effects of response-contingent and response-independent nicotine in rats. Eur J Pharmacol 402: 231-240.

Forget B, Coen KM, Le Foll B (2009). Inhibition of fatty acid amide hydrolase reduces reinstatement of nicotine seeking but not break point for nicotine self-administration-comparison with $\mathrm{CB}(1)$ receptor blockade. Psychopharmacology (Berl) 205: 613-624.

Fu J, Gaetani S, Oveisi F, Lo Verme J, Serrano A, Rodriguez De Fonseca $\mathrm{F}$ et al (2003). Oleylethanolamide regulates feeding and body weight through activation of the nuclear receptor PPARalpha. Nature 425: 90-93.

Gamaleddin I, Guranda M, Goldberg SR, Le Foll B (2011). The selective anandamide transport inhibitor VDM11 attenuates reinstatement of nicotine seeking behaviour, but does not affect nicotine intake. Br J Pharmacol 164: 1652-1660.

Gamaleddin I, Wertheim C, Zhu AZ, Coen KM, Vemuri K, Makryannis A et al (2012). Cannabinoid receptor stimulation increases motivation for nicotine and nicotine seeking. Addict Biol 17: 47-61.

Gerard N, Ceccarini J, Bormans G, Vanbilloen B, Casteels C, Goffin $\mathrm{K}$ et al (2010). Influence of chronic nicotine administration on cerebral type 1 cannabinoid receptor binding: an in vivo micro-PET study in the rat using $\left[{ }^{18} \mathrm{~F}\right] \mathrm{MK}-9470$. J Mol Neurosci 42: $162-167$.

Giuffrida A, Parsons LH, Kerr TM, Rodriguez de Fonseca F, Navarro M, Piomelli D (1999). Dopamine activation of endogenous cannabinoid signaling in dorsal striatum. Nat Neurosci 2: 358-363.

Gonzalez S, Cascio MG, Fernandez-Ruiz J, Fezza F, Di Marzo V, Ramos JA (2002). Changes in endocannabinoid contents in the brain of rats chronically exposed to nicotine, ethanol or cocaine. Brain Res 954: 73-81.
Grieder TE, George O, Tan H, George SR, Le Foll B, Laviolette SR et al (2012). Phasic D1 and tonic D2 dopamine receptor signaling double dissociate the motivational effects of acute nicotine and chronic nicotine withdrawal. Proc Natl Acad Sci USA 109: 3101-3106.

Haj-Dahmane S, Shen RY (2010). Regulation of plasticity of glutamate synapses by endocannabinoids and the cyclic-AMP/ protein kinase A pathway in midbrain dopamine neurons. J Physiol 588(Part 14): 2589-2604.

Hemby SE, Co C, Koves TR, Smith JE, Dworkin SI (1997). Differences in extracellular dopamine concentrations in the nucleus accumbens during response-dependent and responseindependent cocaine administration in the rat. Psychopharmacology (Berl) 133: 7-16.

Hill MN, Karatsoreos IN, Hillard CJ, McEwen BS (2010a). Rapid elevations in limbic endocannabinoid content by glucocorticoid hormones in vivo. Psychoneuroendocrinology 35: 1333-1338.

Hill MN, McLaughlin RJ, Bingham B, Shrestha L, Lee TT, Gray JM et al (2010b). Endogenous cannabinoid signaling is essential for stress adaptation. Proc Natl Acad Sci USA 107: 9406-9411.

Hill MN, McLaughlin RJ, Morrish AC, Viau V, Floresco SB, Hillard CJ et al (2009). Suppression of amygdalar endocannabinoid signaling by stress contributes to activation of the hypothalamicpituitary-adrenal axis. Neuropsychopharmacology 34: 2733-2745.

Hill MN, Patel S, Campolongo P, Tasker JG, Wotjak CT, Bains JS (2010c). Functional interactions between stress and the endocannabinoid system: from synaptic signaling to behavioral output. J Neurosci 30: 14980-14986.

Hu SS, Bradshaw HB, Benton VM, Chen JS, Huang SM, Minassi A et al (2009). The biosynthesis of $\mathrm{N}$-arachidonoyl dopamine (NADA), a putative endocannabinoid and endovanilloid, via conjugation of arachidonic acid with dopamine. Prostaglandins Leukot Essent Fatty Acids 81: 291-301.

Jacobs EH, Smit AB, de Vries TJ, Schoffelmeer AN (2003). Neuroadaptive effects of active versus passive drug administration in addiction research. Trends Pharmacol Sci 24: 566-573.

Jacobs EH, Smit AB, de Vries TJ, Schoffelmeer AN (2005). Longterm gene expression in the nucleus accumbens following heroin administration is subregion-specific and depends on the nature of drug administration. Addict Biol 10: 91-100.

Jacobs EH, Spijker S, Verhoog CW, Kamprath K, de Vries TJ, Smit $\mathrm{AB}$ et al (2002). Active heroin administration induces specific genomic responses in the nucleus accumbens shell. FASEB $J$ 16: 1961-1963.

Jung KM, Mangieri R, Stapleton C, Kim J, Fegley D, Wallace M et al (2005). Stimulation of endocannabinoid formation in brain slice cultures through activation of group I metabotropic glutamate receptors. Mol Pharmacol 68: 1196-1202.

Kortleven C, Fasano C, Thibault D, Lacaille JC, Trudeau LE (2011). The endocannabinoid 2-arachidonoylglycerol inhibits long-term potentiation of glutamatergic synapses onto ventral tegmental area dopamine neurons in mice. Eur J Neurosci 33: 1751-1760.

Le Foll B, Forget B, Aubin HJ, Goldberg SR (2008). Blocking cannabinoid $\mathrm{CB} 1$ receptors for the treatment of nicotine dependence: insights from pre-clinical and clinical studies. Addict Biol 13: 239-252.

Lecca D, Valentini V, Cacciapaglia F, Acquas E, Di Chiara G (2007). Reciprocal effects of response contingent and noncontingent intravenous heroin on in vivo nucleus accumbens shell versus core dopamine in the rat: a repeated sampling microdialysis study. Psychopharmacology (Berl) 194: 103-116.

Leung D, Saghatelian A, Simon GM, Cravatt BF (2006). Inactivation of $\mathrm{N}$-acyl phosphatidylethanolamine phospholipase $\mathrm{D}$ reveals multiple mechanisms for the biosynthesis of endocannabinoids. Biochemistry 45: 4720-4726.

Liu J, Wang L, Harvey-White J, Huang BX, Kim HY, Luquet S et al (2008). Multiple pathways involved in the biosynthesis of anandamide. Neuropharmacology 54: 1-7. 
Long JZ, Nomura DK, Vann RE, Walentiny DM, Booker L, Jin X et al (2009). Dual blockade of FAAH and MAGL identifies behavioral processes regulated by endocannabinoid crosstalk in vivo. Proc Natl Acad Sci USA 106: 20270-20275.

Lupica CR, Riegel AC (2005). Endocannabinoid release from midbrain dopamine neurons: a potential substrate for cannabinoid receptor antagonist treatment of addiction. Neuropharmacology 48: 1105-1116.

Mansvelder HD, Mertz M, Role LW (2009). Nicotinic modulation of synaptic transmission and plasticity in cortico-limbic circuits. Semin Cell Dev Biol 20: 432-440.

Marco EM, Granstrem O, Moreno E, Llorente R, Adriani W, Laviola G et al (2007). Subchronic nicotine exposure in adolescence induces long-term effects on hippocampal and striatal cannabinoid-CB1 and mu-opioid receptors in rats. Eur J Pharmacol 557: 37-43.

Marinelli S, Pascucci T, Bernardi G, Puglisi-Allegra S, Mercuri NB (2005). Activation of TRPV1 in the VTA excites dopaminergic neurons and increases chemical- and noxious-induced dopamine release in the nucleus accumbens. Neuropsychopharmacology 30: 864-870.

Markou A (2008). Review. Neurobiology of nicotine dependence. Philos Trans R Soc Lond Ser B 363: 3159-3168.

Mascia P, Pistis M, Justinova Z, Panlilio LV, Luchicchi A, Lecca S et al (2010). Blockade of nicotine reward and reinstatement by activation of alpha-type peroxisome proliferator-activated receptors. Biol Psychiatry 69: 633-641.

Mascia P, Pistis M, Justinova Z, Panlilio LV, Luchicchi A, Lecca S et al (2011). Blockade of nicotine reward and reinstatement by activation of alpha-type peroxisome proliferator-activated receptors. Biol Psychiatry 69: 633-641.

McFarland K, Lapish CC, Kalivas PW (2003). Prefrontal glutamate release into the core of the nucleus accumbens mediates cocaineinduced reinstatement of drug-seeking behavior. J Neurosci 23: 3531-3537.

Melis M, Carta S, Fattore L, Tolu S, Yasar S, Goldberg SR et al (2010). Peroxisome proliferator-activated receptors-alpha modulate dopamine cell activity through nicotinic receptors. Biol Psychiatry 68: 256-264.

Melis M, Pillolla G, Luchicchi A, Muntoni AL, Yasar S, Goldberg SR et al (2008). Endogenous fatty acid ethanolamides suppress nicotine-induced activation of mesolimbic dopamine neurons through nuclear receptors. J Neurosci 28: 13985-13994.

Melis M, Pistis M, Perra S, Muntoni AL, Pillolla G, Gessa GL (2004). Endocannabinoids mediate presynaptic inhibition of glutamatergic transmission in rat ventral tegmental area dopamine neurons through activation of CB1 receptors. J Neurosci 24: 53-62.

Metaxas A, Bailey A, Barbano MF, Galeote L, Maldonado R, Kitchen I (2010). Differential region-specific regulation of alpha4beta $2^{*}$ nAChRs by self-administered and non-contingent nicotine in C57BL/6J mice. Addict Biol 15: 464-479.

Oleson EB, Beckert MV, Morra JT, Lansink CS, Cachope R, Abdullah RA et al (2012). Endocannabinoids shape accumbal encoding of cue-motivated behavior via CB1 receptor activation in the ventral tegmentum. Neuron 73: 360-373.
Orejarena MJ, Berrendero F, Maldonado R, Robledo P (2009). Differential changes in mesolimbic dopamine following contingent and non-contingent MDMA self-administration in mice. Psychopharmacology (Berl) 205: 457-466.

Paxinos G, Watson C (1998): In: The Rat Brain in Stereotaxic Coordinates. Academic Publishers: San Diego, CA.

Peoples LL, West MO (1996). Phasic firing of single neurons in the rat nucleus accumbens correlated with the timing of intravenous cocaine self-administration. J Neurosci 16: 3459-3473.

Pike N (2011). Using false discovery rates for multiple comparisons in ecology and evolution. Methods Ecol Evol 2: 278-282.

Ross HR, Gilmore AJ, Connor M (2009). Inhibition of human recombinant T-type calcium channels by the endocannabinoid $\mathrm{N}$-arachidonoyl dopamine. Br J Pharmacol 156: 740-750.

Saghatelian A, McKinney MK, Bandell M, Patapoutian A, Cravatt BF (2006). A FAAH-regulated class of $N$-acyl taurines that activates TRP ion channels. Biochemistry 45: 9007-9015.

Scherma M, Panlilio LV, Fadda P, Fattore L, Gamaleddin I, Le Foll B et al (2008). Inhibition of anandamide hydrolysis by cyclohexyl carbamic acid 3'-carbamoyl-3-yl ester (URB597) reverses abuserelated behavioral and neurochemical effects of nicotine in rats. J Pharmacol Exp Ther 327: 482-490.

Shoaib M (2008). The cannabinoid antagonist AM251 attenuates nicotine self-administration and nicotine-seeking behaviour in rats. Neuropharmacology 54: 438-444.

Simon GM, Cravatt BF (2008). Anandamide biosynthesis catalyzed by the phosphodiesterase GDE1 and detection of glycerophospho-N-acyl ethanolamine precursors in mouse brain. $J$ Biol Chem 283: 9341-9349.

Smith JE, Co C, Freeman ME, Lane JD (1982). Brain neurotransmitter turnover correlated with morphine-seeking behavior of rats. Pharmacol Biochem Behav 16: 509-519.

Smith JE, Koves TR, Co C (2003). Brain neurotransmitter turnover rates during rat intravenous cocaine self-administration. $\mathrm{Neu}$ roscience 117: 461-475.

Stella N, Piomelli D (2001). Receptor-dependent formation of endogenous cannabinoids in cortical neurons. Eur J Pharmacol 425: 189-196.

Stuber GD, Roitman MF, Phillips PE, Carelli RM, Wightman RM (2005). Rapid dopamine signaling in the nucleus accumbens during contingent and noncontingent cocaine administration. Neuropsychopharmacology 30: 853-863.

Szabo B, Siemes S, Wallmichrath I (2002). Inhibition of GABAergic neurotransmission in the ventral tegmental area by cannabinoids. Eur J Neurosci 15: 2057-2061.

Tronci V, Balfour DJ (2011). The effects of the mGluR5 receptor antagonist 6-methyl-2-(phenylethynyl)-pyridine (MPEP) on the stimulation of dopamine release evoked by nicotine in the rat brain. Behav Brain Res 219: 354-357.

Werling LL, Reed SC, Wade D, Izenwasser S (2009). Chronic nicotine alters cannabinoid-mediated locomotor activity and receptor density in periadolescent but not adult male rats. Int $J$ Dev Neurosci 27: 263-269.

You ZB, Wang B, Zitzman D, Azari S, Wise RA (2007). A role for conditioned ventral tegmental glutamate release in cocaine seeking. J Neurosci 27: 10546-10555.

Supplementary Information accompanies the paper on the Neuropsychopharmacology website (http://www.nature.com/npp) 